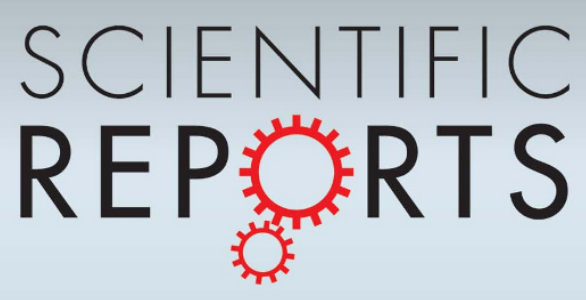

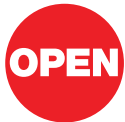

SUBJECT AREAS:

EVOLUTION

POPULATION GENETICS

COMPUTATIONAL BIOLOGY

MICROBIOLOGY

Received

12 October 2011

Accepted

10 January 2012

Published

30 January 2012

Correspondence and requests for materials should be addressed to

I.K. (ikobaya@ims. u-tokyo.ac.jp)

\section{Success of a suicidal defense strategy against infection in a structured habitat}

\author{
Masaki Fukuyo ${ }^{1,2}$, Akira Sasaki ${ }^{3,4}$ \& Ichizo Kobayashi ${ }^{1,5,6}$
}

\begin{abstract}
'Department of Medical Genome Sciences, Graduate School of Frontier Sciences, University of Tokyo, Tokyo 108-8639, Japan, ${ }^{2}$ Research Fellow of the Japan Society for the Promotion of Science (JSPS), ${ }^{3}$ Department of Evolutionary Studies of Biosystems (Sokendai-Hayama), The Graduate University for Advanced Studies (Sokendai), Hayama, Kanagawa 240-0193, Japan, ${ }^{4}$ Evolution and Ecology Program, International Institute for Applied Systems Analysis, Laxenburg, Austria, ${ }^{5}$ Institute of Medical Science, University of Tokyo, Tokyo, Japan, 'Department of Biophysics and Biochemistry, Graduate School of Science, University of Tokyo, Tokyo, Japan.
\end{abstract}

Pathogen infection often leads to the expression of virulence and host death when the host-pathogen symbiosis seems more beneficial for the pathogen. Previously proposed explanations have focused on the pathogen's side. In this work, we tested a hypothesis focused on the host strategy. If a member of a host population dies immediately upon infection aborting pathogen reproduction, it can protect the host population from secondary infections. We tested this "Suicidal Defense Against Infection" (SDAI) hypothesis by developing an experimental infection system that involves a huge number of bacteria as hosts and their virus as pathogen, which is linked to modeling and simulation. Our experiments and simulations demonstrate that a population with SDAI strategy is successful in the presence of spatial structure but fails in its absence. The infection results in emergence of pathogen mutants not inducing the host suicide in addition to host mutants resistant to the pathogen.

W hy do some organisms succumb and die easily when infected? Microbial infection often leads to expression of virulence and host death when symbiosis seems more beneficial for the infecting microbe's maintenance. Previously proposed concepts have focused on the pathogen's strategy and they provide only partial explanations, such as better reproduction ${ }^{1}$, incomplete adaptation after a host jump ${ }^{2}$, and within-host competition ${ }^{3}$.

In multicellular organisms, cells infected with pathogens often undergo programmed death to end their propagation and prevent secondary infection of neighboring cells ${ }^{4}$. Virulence and transmissibility are negatively correlated in some pathogens, such as influenza virus ${ }^{5}$. Based on these considerations, we propose a hypothesis focused on the host strategy. If a member of a host population dies immediately upon infection with a pathogen, thereby ending its reproduction, then its death could protect the host population from secondary and further infections (Fig. 1; Fig. 2a). Indeed, bacterial suicide aborting virus (bacteriophage) multiplication has long been known as phage exclusion ${ }^{6}$, but the selective pressures resulting in this traits have received little attention.

We tested this "Suicidal Defense Against Infection" (SDAI) hypothesis by developing an experimental infection system containing a large number $(100,000,000)$ of hosts, which was linked to mathematical modeling and computer simulation. The unicellular bacterium Escherichia coli and bacteriophage lambda, well studied for long time, were used as the model host and pathogen. The infection was conducted either in the presence of spatial structure (within soft agar) or its absence (in a well-mixed liquid).

Our experiments and simulation demonstrated that the SDAI strategy is successful in the presence of spatial structure but unsuccessful in its absence.

\section{Results}

Experimental design. We prepared two host strains: susceptible type $S$ that allows multiplication of the pathogen when infected (Fig. 2a(i)) and altruistic type A that immediately commits suicide when infected with pathogen $\mathrm{P}$ (SDAI strategy, see Introduction) (Fig. 2a(ii)). The former type without SDAI strategy will be referred to as nonaltruistic for contrast. The pathogen P (Fig. 2a) was bacteriophage lambda carrying a DNA methyltransferase gene ${ }^{7}$. Upon entering a host, the methyltransferase produced by this pathogen starts methylating the host genome. A DNase in host A cleaves the genome near the methylated sites, which leads to host death. Host $\mathrm{S}$ lacks this DNase. Pathogen Q lacked the DNA methyltransferase and could not induce suicide in either host. These relationships are shown in Fig. $2 \mathrm{~b}$. 

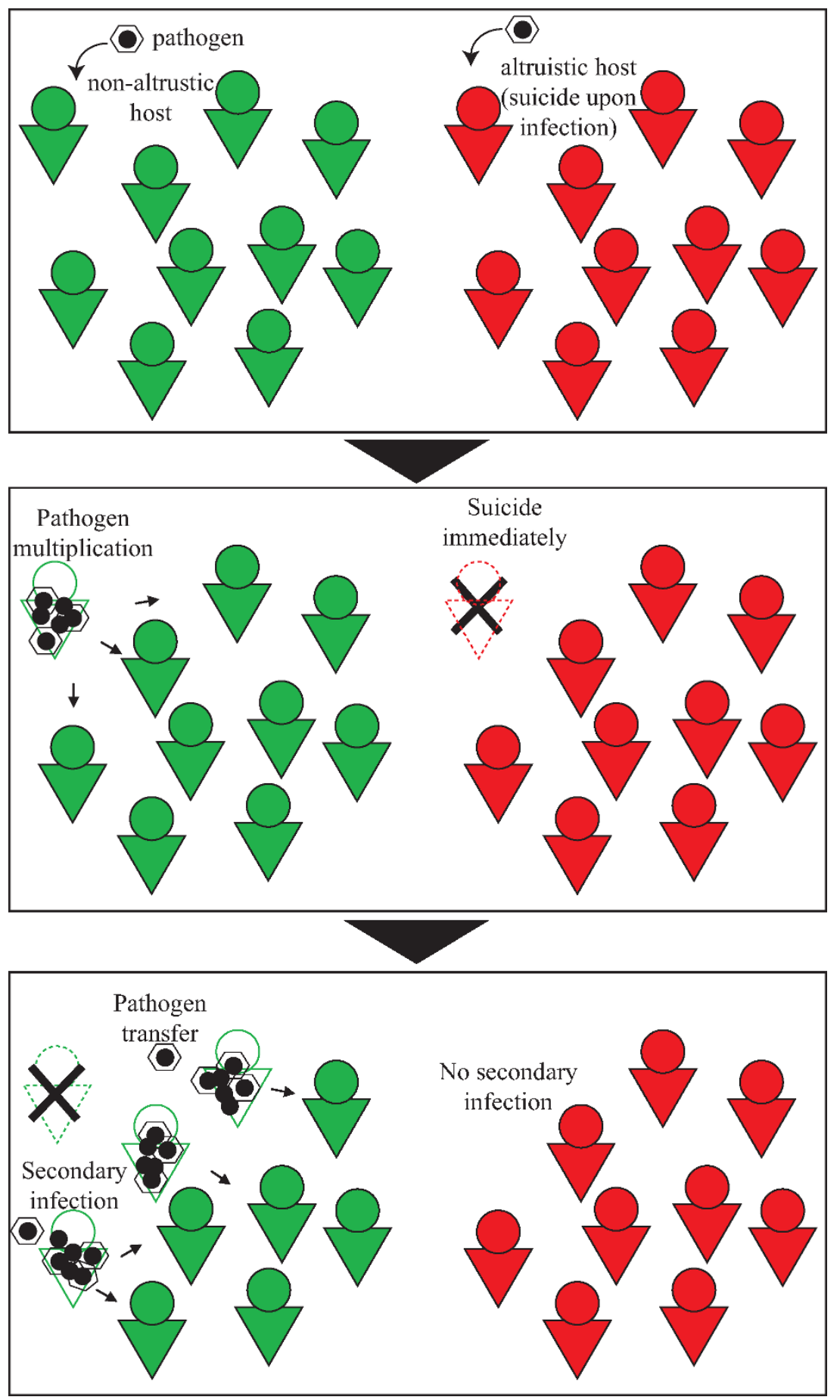

Figure 1 Summary diagram of the success of the Suicidal Defense Against Infection (SDAI) strategy in the presence of spatial structure. Nonaltruistic hosts and altruistic hosts were found in a colony. The non-altruistic colony spreads infection, whereas the altruistic host colony prevents spread of infection due to the altruistic suicide of an infected member.

Fig. 2c illustrates the experimental procedure. We mixed the two hosts, A (altruistic) and S (non-altruistic), at various ratios and infected them with pathogen $\mathrm{P}$, before monitoring any change in the ratio. Spatial structure is important in interaction between organisms $\mathrm{s}^{8-14}$, so we used two infection conditions: standing soft agar provided spatial structure, thereby ensuring that individuals preferentially interacted with their neighbors, and a well-mixed liquid where spatial structure was absent, which is expected to allow any individual to interact with any other individual with an equal frequency.

Time course of infection. The time course of the infection experiments is analyzed in Fig. 3a, b. In the presence of spatial structure (Fig. 3a), pathogen increase was accompanied by a gradual increase in the $A: S$ ratio, eventually by two orders of magnitude $(1 / 1000$ to $1 / 10)$. This demonstrates that the SDAI strategy facilitated a relative increase in host A. In contrast, pathogen increase was accompanied by a decrease in the A:S ratio when spatial structure was absent (Fig. 3b). These results clearly indicated that the infection conditions played an important role in the success of the SDAI strategy. The unexpected decrease in the ratio when spatial structure was absent will be addressed later.

Varying the ratio of the hosts. We then investigated the final A:S ratio as a function of the initial A:S ratio (Fig. $3 e, f$ ) along with a 
(a)

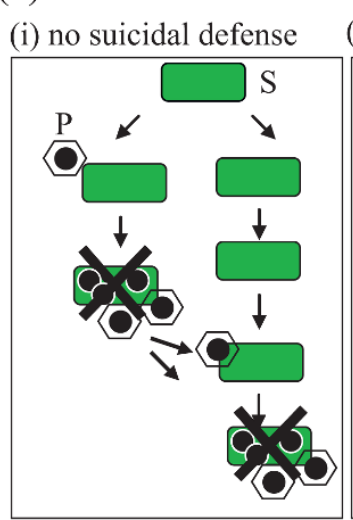

(ii) suicidal defense

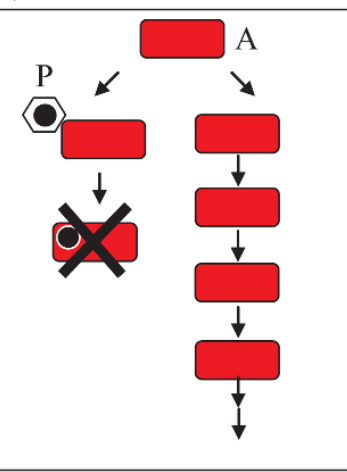

(c)

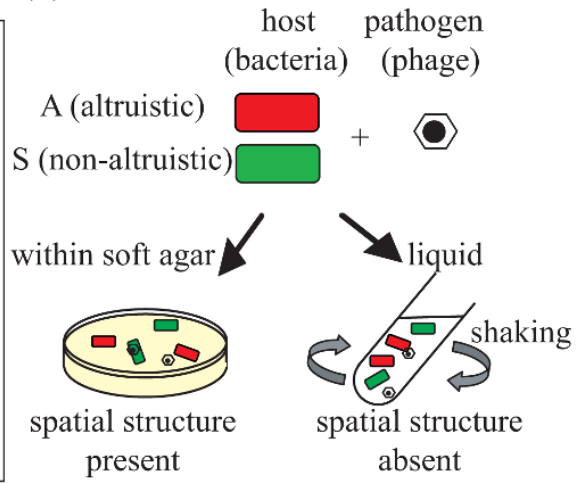

(b)

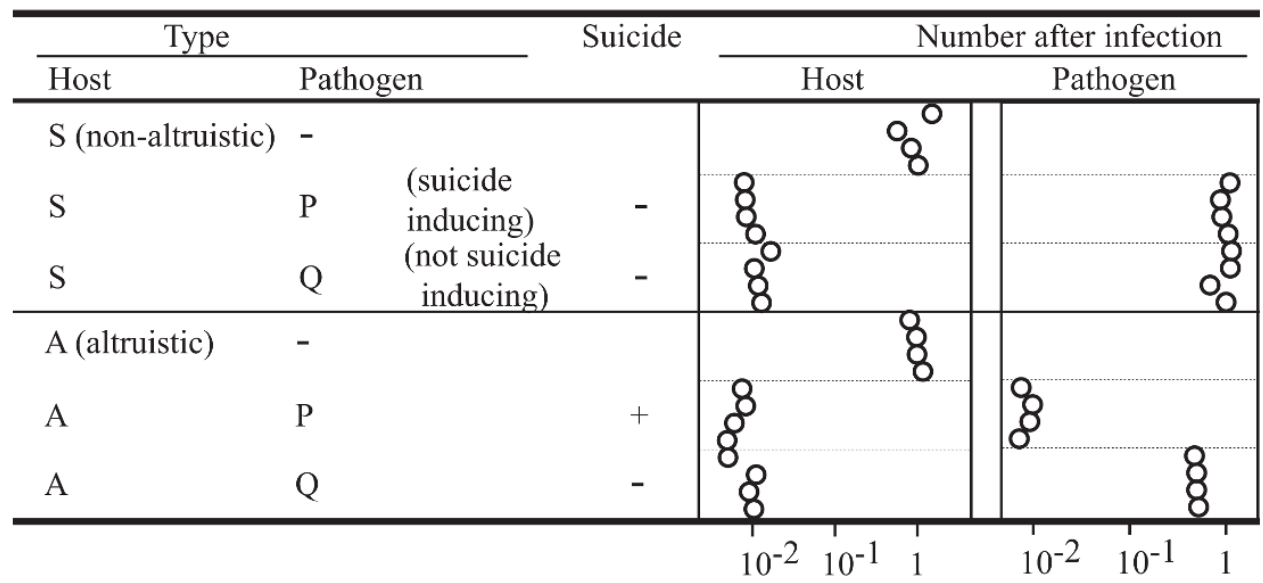

Figure $2 \mid$ Design. (a) Concept of "Suicidal Defense Against Infection" (SDAI). (i) A host of the non-altruistic (non-suicidal) type S allows propagation of pathogen $\mathrm{P}$ and secondary infection of other hosts. (ii) A host of the altruistic (suicidal) type A commits suicide immediately after infection, thereby ending pathogen multiplication and preventing secondary infection of other hosts. (b) Survival of the host and the pathogen after infection. The host number (relative colony-forming units) was measured in the presence of excess pathogens. The pathogen number (relative plaque-forming units) was measured in the presence of excess hosts. See Materials and methods for the genotype of the hosts (Escherichia coli) and the pathogens (bacteriophage lambda). (c) Experimental procedure. The two types of host were mixed at a varying ratio, challenged by the pathogen, and incubated under two different conditions: one with spatial structure and the other without. Change in the ratio was monitored. See Materials and methods for detail.

control lacking the pathogen. In the experiments with spatial structure (Fig. 3e) and without the pathogen, the ratio changed very little. The slight downward shift of the line without any pathogen is reproducible and might reflect a growth disadvantage of host $\mathrm{A}$. The increase in the A:S ratio in the presence of pathogen $\mathrm{P}$ was the largest with the lowest initial A:S ratio (1/1000) and insignificant at the highest A:S ratio (1000). There is negative relationship between relative fitness (= rational increase in $\mathrm{A}: \mathrm{S}$ ) of host $\mathrm{A}$ and the initial A:S ratio. The relationship can be described by a power function $\mathrm{y}=8.32 \mathrm{x}^{-0.282}, \mathrm{R}^{2}=0.877$.

In experiments where spatial structure and the pathogen were absent (Fig. 3f), the ratio changed very little, although it decreased slightly at the highest initial ratio. With pathogen $\mathrm{P}$ in the absence of spatial structure, the A:S ratio decreased by two orders of magnitude, from $1 / 1000$ to $1 / 100000$. This decrease emphasizes the contrast between the conditions with and without spatial structure.

Observation of microcolonies. Fig. 4a and b show fluorescent microscope images of the host microcolonies, where the two hosts were labeled using different fluorescent proteins. A and S microcolonies grew normally when the pathogen was not present (Fig. 4a). However, S microcolonies were destroyed after infection with pathogen $\mathrm{P}$, whereas A microcolonies grew even when surrounded by the pathogen source (Fig. $4 \mathrm{~b}$ ).
Emergence of host mutants resistant to the pathogen. The decrease in A:S ratio in the absence of spatial structure at the low initial ratio might be explained by mutations in the host and/ or pathogen, which are expected to occur with this type of experimental infection ${ }^{15}$. Thus, we analyzed their genotype after the infection.

In the absence of spatial structure, hosts $\mathrm{A}$ and $\mathrm{S}$ were found to be replaced by pathogen-resistant mutants after $16 \mathrm{~h}$ of incubation. In the presence of pathogen $\mathrm{P}$, the fraction of resistant mutants increased from $2.70 \pm 0.18 \times 10^{-6}$ to $0.94 \pm 0.06$ for host $\mathrm{S}$ and from $3.59 \pm 0.49 \times 10^{-6}$ to $1.11 \pm 0.16$ for host $\mathrm{A}$ $(n=4)$. These results explain the decrease in A:S ratio in the absence of spatial structure at the low initial ratio (Fig. 3f, h). The host A population was too small to initially harbor the pathogenresistant mutants. This point will be confirmed by simulation later.

On the other hand, there is no decrease in S:A ratio (= no increase in A:S ratio) at the low initial S:A ratio (at the high initial A:S ratio) (Fig. 3f). Likely because of lack of hosts (S) that allow multiplication of the pathogen, infection does not expand to provide selection for the host mutants. Consistent with this interpretation, host S:A ratio slightly decreased (A:S ratio increased) at the S:A ratio of 1: 1000 (A:S ratio of 1000:1) with control pathogen $\mathrm{Q}$, which does not induce host suicide (Fig. 2b; Fig. S1b). 
(a) with spatial structure, experiment

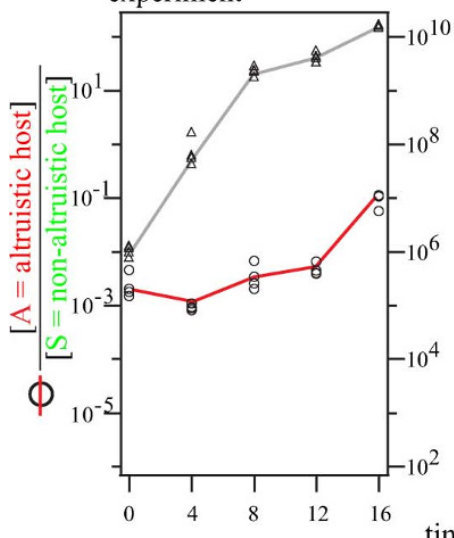

(c) with spatial structure,

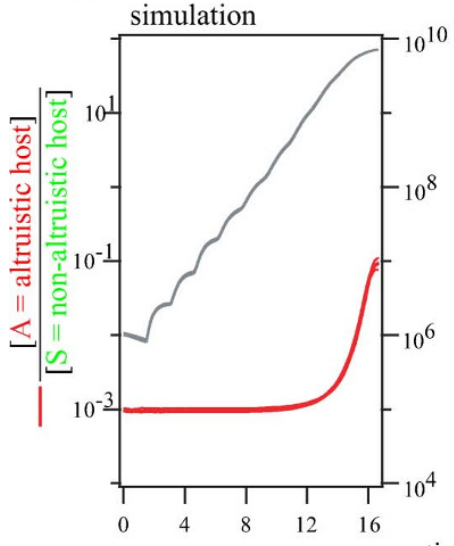

(b) without spatial structure, experiment

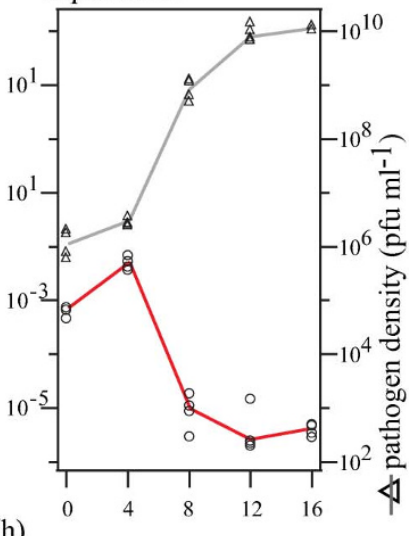

(d) without spatial structure,

simulation

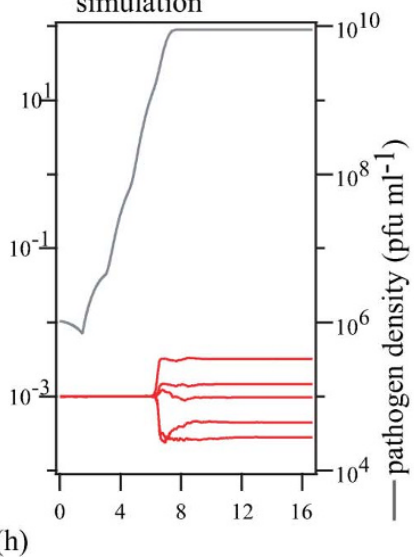

— without pathogen

- with pathogen (P)

(e) with spatial structure,

(f) without spatial structure, experiment

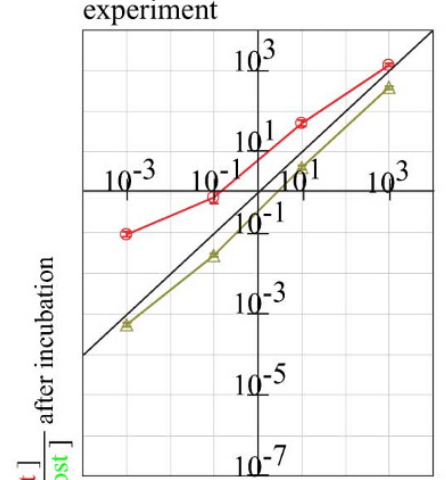

(g) with spatial structure, simulation

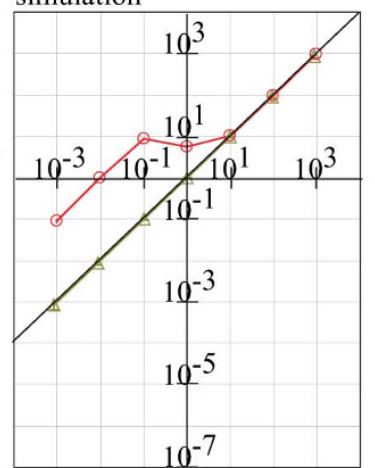

initial $\frac{[\mathrm{A}=\text { altruistic host }]}{[\mathrm{S}=\text { non-altruistic host }]}$

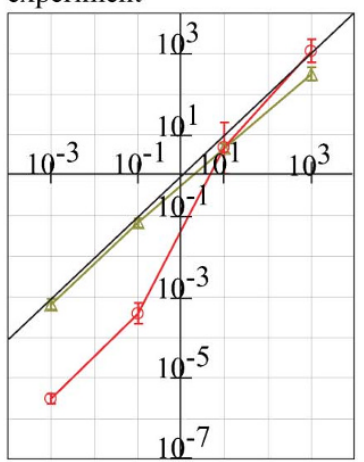

(h) without spatial structure, simulation
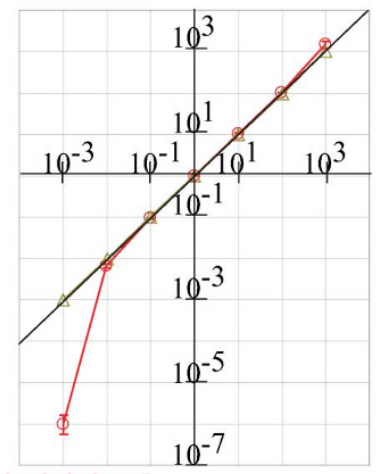

time (h)

Figure $3 \mid$ Changes in the ratio of the altruistic (suicidal) host to the non-altruistic (non-suicidal) host during infection. (a-d) Time course. $\mathrm{N}=4$ in experiments and 5 in simulations. (e-h) Varying input ratio. The initial ratio of the altruistic (suicidal) host to the non-altruistic (non-suicidal) host was varied (horizontal axis). The ratio was measured after $16 \mathrm{~h}$ of incubation in experiments and after a simulation time of $16.7 \mathrm{~h}$ (vertical axis). The averages \pm SEM $(\mathrm{N}=4)$ are shown for experiments. The results from 100 runs are shown for simulations. (For individual simulation results for h, see Fig. S2).

Emergence of pathogen mutants not inducing host death. After the above infection experiments, we found mutants of pathogen $\mathrm{P}$ that were defective in inducing host suicide, just as the control pathogen Q (Fig. 5a). These mutants could grow in host A as well as host $\mathrm{S}$ (Fig. 5b, blue circle). Sequencing showed that they carried different mutations in the methyltransferase gene that induces the suicide (Fig. 5a). Each tube used for infection contained multiple mutants (Fig. 5a, b, Table S1). Methyltransferase activity was estimated based on growth in the presence of restriction enzyme that cleaves the pathogen genome at its unmethylated sites. The activity level varied among the mutants, but it was similar in those mutants from the same tube (Fig. 5b, red triangle). Based on these, we estimated the number of mutants defective in inducing host suicide that emerged from the infection process (Fig. 5c).

We found that more mutants appeared with a higher initial A:S ratio, which was likely because host A selects them. In the absence of spatial structure and with a high initial A:S ratio, the pathogen population was entirely replaced by this type of mutants (Fig. $5 c$ (ii)). In the presence of spatial structure and with a high initial A:S ratio, we see similar trends but less extreme replacements. In the presence of spatial structure, spatial refuge likely restricts frequency of the infection events and selection pressure for pathogen mutants may be weaker than that in the absence of spatial structure.

Mathematical modeling and simulation. We conducted mathematical modeling and computer simulations using a large double-lattice with $10000 \times 10000$ cells in the presence of spatial structure and with a population of $10^{8}$ in the absence of spatial structure (see Materials and methods for detail). Our simulation (Fig. 3c, d) reproduced the essential features of our experimental results. Thus, in the presence of spatial structure, a pathogen increase was followed by an increase in the ratio of the two hosts (A:S) of two orders of magnitude. The essential features of our experimental results with other input ratios were also reproduced in the simulations (Fig. $3 \mathrm{~g}, \mathrm{~h}$ ).

In the absence of spatial structure, the pathogen increase was followed by a random (unpredictable) change in the A:S ratio (Fig. 3d). These changes were not biased in a large enough population $\left(10^{10}\right)$, but they were biased towards decrease in a smaller population $\left(10^{8}\right)$ (Fig. S2). We also observed the extinction (58/100) of host A at a population size of $10^{8}$. Therefore, the decrease in the A:S ratio observed in the experiments (Fig. 3f, h) was probably due to limited population size, as discussed above. The host population members were replaced by mutants resistant to the pathogen (as described above). The smaller population could not initially harbor the resistant mutations, so there was a delay before their appearance. This explanation is consistent with the simulation and the experimental results. Our detailed time course analysis treating A host density and S host density separately confirmed this interpretation (Fig. S3). The delay in acquiring a pathogen-resistant mutation apparently led to decrease in the A:S ratio (Fig. $S 3 b(i i)$ ).

Fig. 4 c, d show snapshots of a $100 \times 100$ area of the host lattice in the simulation (see Supplemental animations for detail). The altruistic (suicidal) type host A (red) represents a minor (1/1000) proportion of the population (Fig. 4c). The non-altruistic (non-suicidal) 
green: $\mathrm{S}$ (non-altruistic host) red: A (altruistic host)

(a) initial $\mathrm{A}: \mathrm{S}=10^{-1}$ without pathogen

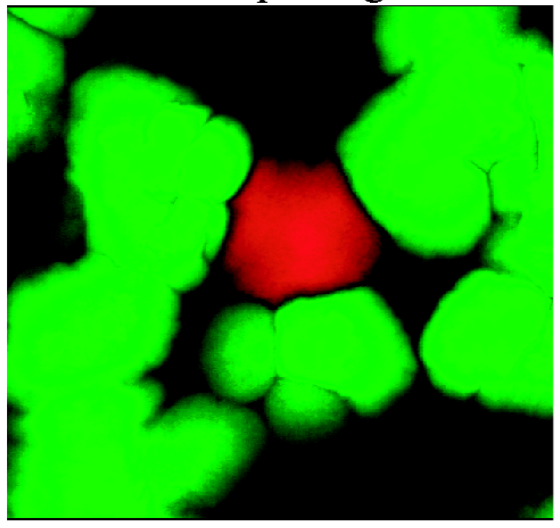

(b) initial $\mathrm{A}: \mathrm{S}=10^{-1}$
with pathogen $\mathrm{P}$

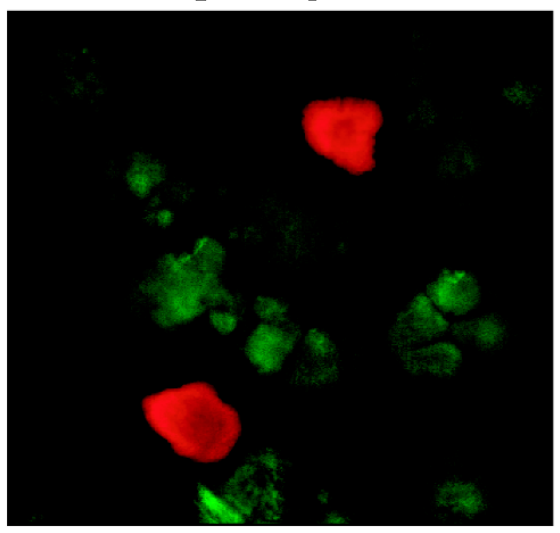

$\square$ empty

$\mathrm{S}$ (non-altruistic host) I (infected host)

\section{A (altruistic host)}

(c) initial $\mathrm{A}: \mathrm{S}=10^{-3}$

$\mathrm{t}$
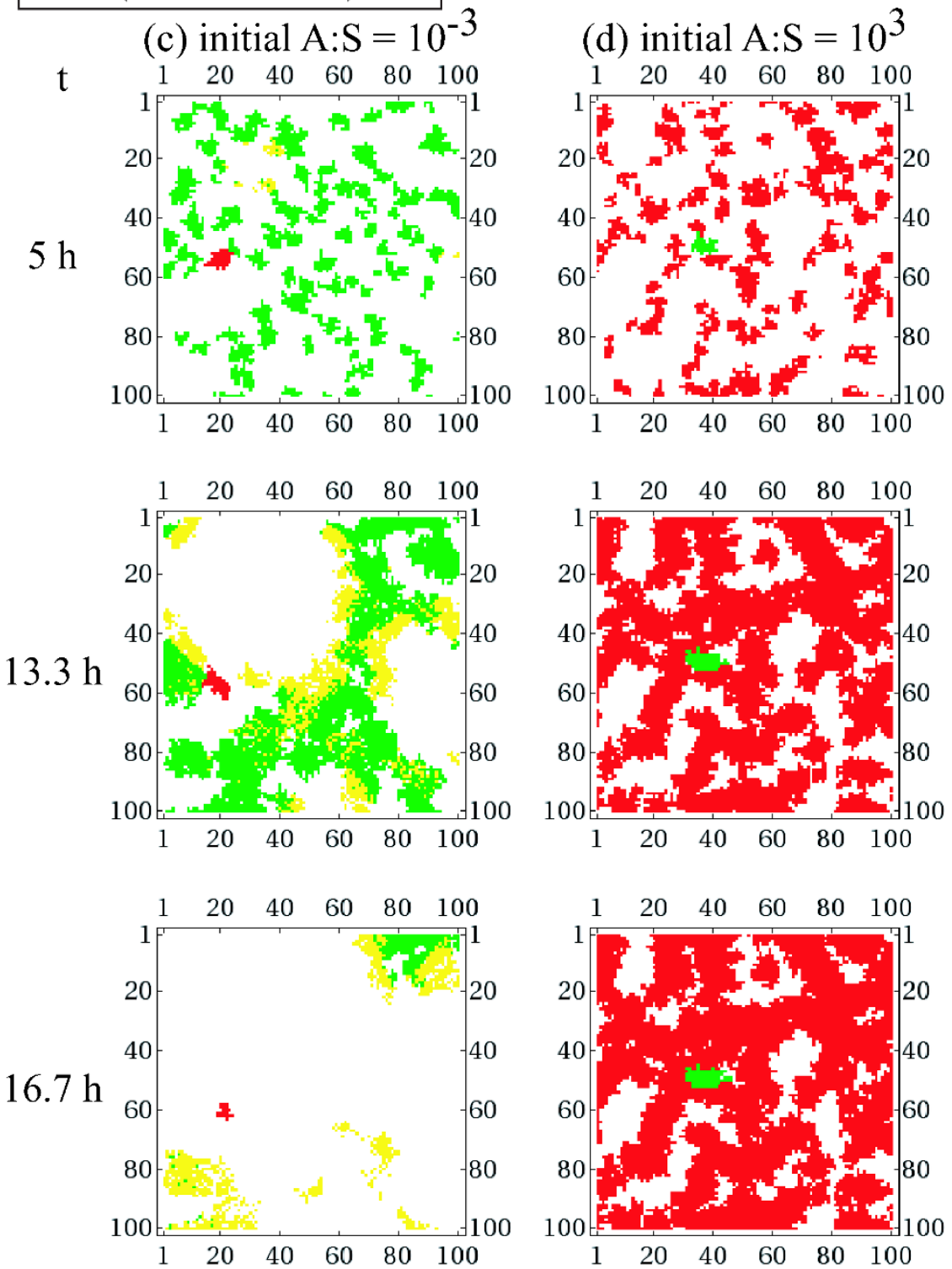

Figure $4 \mid$ Snapshots in the presence of spatial structure. (a), (b): from experiments. The susceptible (non-altruistic) host $S$ was labeled with a green fluorescent protein, while the altruistic host A was labeled with a red fluorescent protein (see Materials and methods for detail). $16 \mathrm{~h}$ after infection. (c), (d): from simulation. A $100 \times 100$ area of the $256 \times 256$ lattice is shown.

host $S$ (green) mediated a pandemic as indicated by the spread of the infected non-altruistic type host I (yellow). The altruistic host A (red) survived in a colony even when the neighboring non-altruistic host $\mathrm{S}$ colonies were eradicated during the pandemic. This resulted in a large increase in the A:S ratio after infection.

When the altruistic host A predominated in the population (Fig. 4d), a pandemic was not observed, because infection was prevented from spreading by the altruistic host A population surrounding the non-altruistic host $S$ colony. This resulted in no great increase in the A:S ratio. This indicates that the altruistic host A could not eliminate the host S. An altruistic host allows neighboring altruistic and non-altruistic hosts to escape infection in a structured habitat. Thus, the altruistic host A is effectively parasitized by the freeloading S host.
Our simulation reproduced features of the emergence of the pathogen mutants not inducing host suicide (Fig. S4). When host A (suicidal) is more than host $S$ (two initial conditions) in the absence of spatial structure, the pathogen population is replaced by such mutants. In the presence of spatial structure, we see similar trends but less extreme replacements. We show the simulation of how the fraction of mutants changes with time in the absence of spatial structure in Fig. S3b(ii). Pathogen increase (Fig. S3b(i)) was accompanied by increases in the host mutant frequency and a decrease in the A:S ratio. In the presence of spatial structure, infection proceeded slowly and led to pathogen increase at the last phase. This was accompanied by decrease of the type $S$ host and increase of their pathogen resistant mutants. This did not happen to the type A host (Fig. S3c). 

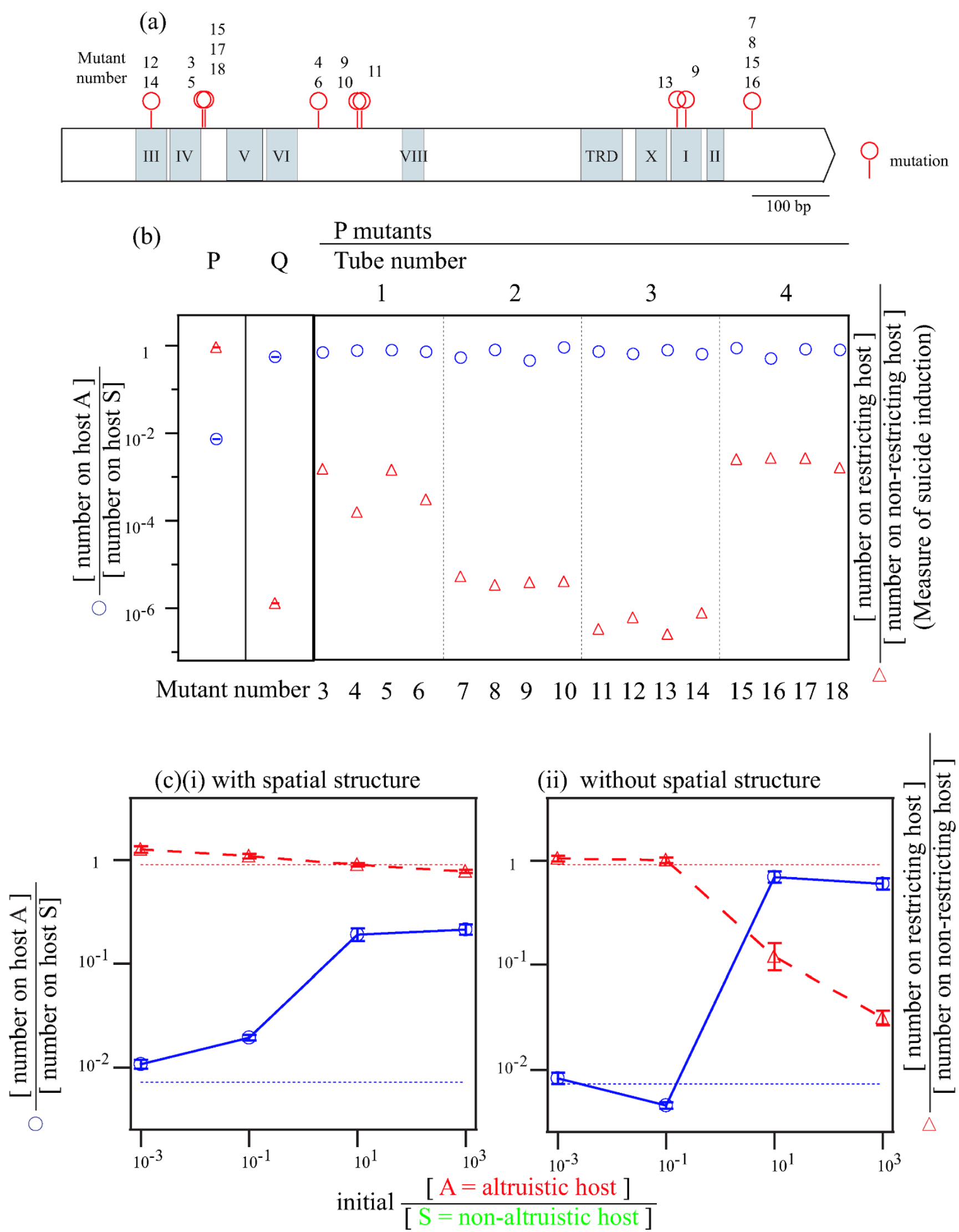

Figure 5 Emergence of pathogen mutants defective in inducing host suicide. (a) Mutations in the DNA methyltransferase gene in mutants recovered after infection in the absence of spatial structure (initial A:S $=10^{3}$ ). Roman numerals refer to motifs characteristic of DNA methyltransferases. See Table S1 for details of the mutants. (b) Characterization of the mutants. The ratio of the number measured in a restricting host (PvuII ${ }^{+}$) to the number measured in a non-restricting host $\left(\mathrm{PvuII}^{-}\right)$is a measure of defects in the pathogen's DNA methyltransferase (M.PvuII) activity, which induced suicide in host A. (c) Dependency of the mutant pathogen emergence on spatial structure and the initial host ratio. 


\section{Discussion}

Our results of infection experiments and simulations (Fig. 3) clearly indicate that a "Suicidal Defense Against Infection" (SDAI) strategy (Fig. 1; Fig. 2a) can evolve in the presence of spatial structure. In a simple example, the hosts in the internal part of an altruistic host colony would be protected by suicide of the individuals placed in its external part (Fig. 4). In the absence of spatial structure, however, altruistic hosts would be infected with pathogens from non-altruistic hosts, and nonaltruistic hosts would also be protected by altruistic hosts. Spatial structure plays an important role in the kin selection-based theory of altruism ${ }^{16}$. It is natural that spatial structure governs benefits of this extreme form of altruism based on kin selection.

The maximum benefit of SDAI strategy in the presence of spatial structure was obtained at the minimum initial A:S ratio (Fig. 3e). The higher the initial A:S ratio, the smaller the SDAI strategy benefit (Fig. 3e). Spread of infection among the non-altruistic hosts was presumably blocked by the surrounding altruistic hosts, when A:S ratio became larger. The SDAI strategy can invade the non-SDAI strategy and it is stable once established. However, it cannot eliminate the non-SDAI strategy. Such negative frequency dependence of altruist's fitness was expected from theory of social evolution in structured populations with strong selection ${ }^{17}$.

These results imply that virulence is a property, or function, of a host-pathogen interaction but not of a pathogen only. We revealed that the host strategy of inducing high virulence in the pathogen upon infection has the advantage of preventing pathogen spread. We realize a paradoxical competition between a host and a pathogen with respect to virulence. Thus, if the pathogen favors less virulence to avoid host death and maintain sustainable symbiosis, the host favors more induced virulence to prevent the pathogen form spreading. This is similar to arms race between pathogen infectivity and host resistance ${ }^{8}$. Indeed, there was emergence of pathogen mutants defective in inducing host suicide (less virulent mutants) under some conditions (Fig. 5).

Previous studies show that the presence of spatial structure can provide an advantage to less virulent pathogens ${ }^{13}$. Under our two conditions, the fraction of less virulent mutants appeared lower in the presence of spatial structure (Fig. S4). However, these two conditions cannot be directly compared: selective pressure was weak in the presence of spatial structure due to the limited extent of infection.

Other examples of suicidal altruism in unicellular bacteria have been reported such as those accompanying production of bacterio$\operatorname{cin}^{12}$ and stimulation of immune response ${ }^{18}$. Suicidal defense against infection is seen in multi-cellular organisms at the level of cells, such as programmed death of infected mammalian and plant cells ${ }^{19}$, and at the level of individuals, such as self-removal of infected individuals in social insects ${ }^{20}$.

In this work, the unicellular bacterium Escherichia coli and bacteriophage lambda, well studied for long time, were used as the model host and pathogen to study infection. However, our modeling took a general form not limited to pairs of bacteria and bacteriophage, so our experiment-simulation system will be useful for analysis of other forms of infection and biological interactions in general.

\section{Methods}

Bacterial strains, bacteriophage strains, and plasmids. The E. coli $\mathrm{K}-12$ strains, phages, and plasmids used are listed in Table S2. The nonsuicidal type strain (BMF5, mcrB::kan, designated as $\mathrm{S}$ host in this study) was kanamycin-resistant and $l a c Z^{+}$, whereas the suicidal type strain (BMF3, $m c r B C^{+}$, A host) was chloramphenicolresistant and $l a c Z^{-}$. McrBC is a methyl-specific DNase. Biable counts (colony counts) can be selectively measured on agar plates containing kanamycin and agar plates containing chloramphenicol, so they can be differentially scored based on colony color on a special agar plate. The $\mathrm{P}$ pathogen that induced suicide in the $\mathrm{S}$ host was bacteriophage lambda carrying a gene for PvuII DNA methyltransferase, whereas the $Q$ pathogen did not carry this gene. The lambda phage used in this work was int but $c I^{+}$. Therefore, stable lysogeny is impossible, but temporary immune state under some of the conditions cannot be excluded. However, presence of such temporary immunity, if any, does not affect our main conclusion that the altruistic host has advantage in the presence of spatial structure because presence of such temporary immunity should make the results with pathogen $(\mathrm{P})$ closer to the results without pathogen. In our experiments in Fig. 3(e), the altruistic host (red line) showed clear advantage over non-altruistic host with pathogen as opposed to the case without pathogen (olive line). We have not incorporated such temporary lysogeny into the model, so we do not know whether it explains the difference between the experimental results and the simulation results.

A $0.7 \mathrm{~kb}$ fragment, including the $m r f p$ or $g f p u v$ gene, was amplified from $p N G 1^{21}$ or pSHINE2121 ${ }^{22}$ using mRFP-1 (5' - CCagatctATGGCCTCCTCCGAGGACGTCAT $\left.3^{\prime}\right)$ and mRFP-2 (5' - GGgaattcTTAGGCGCCGGTGGAGTGGCGGC-3') primers or GFPuv-1 (5' - CCagatctATGAGTAAAGGAGAAGAACTTTT-3') and GFPuv-2 (5' - GGgaattcTTATTTGTAGAGCTCATCCATGC-3') primers. Each PCR primer had an introduced restriction site, for BglII and EcoRI, at the $5^{\prime}$ end (small letters). The fragment was digested with BglII and EcoRI and inserted into pUC19 (laboratory collection) to generate pMF8 (pUC19-mrfp: Amp) or pMF9 (pUC19-gfpuv: Amp).

Growth medium. Host $E$. coli cells were grown in tryptone-maltose broth with $10 \mathrm{mM} \mathrm{MgSO}_{4}$ (TM10. $1.0 \%$ (w/v) tryptone, $0.5 \%$ (w/v) $\mathrm{NaCl}, 0.2 \%$ (w/v) maltose, and $10 \mathrm{mM} \mathrm{MgSO}_{4}$ ). Antibiotics were added at the following concentrations as required: kanamycin (Kan) $20 \mu \mathrm{g} \mathrm{mL}^{-1}$ and chloramphenicol $(\mathrm{Cml}) 25 \mu \mathrm{g} \mathrm{mL}^{-1}$.

Bacterial growth. Overnight cultures of hosts were diluted 100-fold and grown at $37^{\circ} \mathrm{C}$ in TM10. When the cultures reached the mid-exponential phase, its cell concentration was adjusted to $10^{8}$ cells $\mathrm{mL}^{-1}$ for storage at $4^{\circ} \mathrm{C}$.

Phage preparation and plaque assay. P1 vir was prepared on JC8679, and LEF1 was prepared on BMF1, using the plate lysate $\operatorname{method}^{23}$. For the phage plaque assay, an overnight culture of E. coli was diluted 100-fold and grown to mid-exponential phase at $37^{\circ} \mathrm{C}$ with aeration in TM10. Phage was diluted appropriately and mixed with the culture. After incubation at room temperature for $10 \mathrm{~min}$, the phage-bacteria complex was mixed with $2 \mathrm{~mL}$ of lambda polypeptone top agar $(1.0 \%(\mathrm{w} / \mathrm{v})$ polypeptone, $0.5 \%(\mathrm{w} / \mathrm{v}) \mathrm{NaCl}, 0.2 \%$ maltose, $10 \mathrm{mM} \mathrm{MgSO}_{4}$, and $0.6 \%$ Bactoagar) and poured on lambda polypeptone bottom agar $(1.0 \%(\mathrm{w} / \mathrm{v})$ polypeptone, $0.5 \%$ (w/v) $\mathrm{NaCl}, 0.2 \%$ maltose, $10 \mathrm{mM} \mathrm{MgSO}_{4}$, and $1.0 \%$ Bactoagar) plate. Plates were incubated at $37^{\circ} \mathrm{C}$ for $16 \mathrm{~h}$ and plaques were counted.

Infection. To investigate infection in the absence of spatial structure, the two host were mixed in various ratios with a total concentration of $10^{7}$ cell $\mathrm{mL}^{-1}$ in $1 \mathrm{~mL}$ of TM10. We then added $10^{6}$ plaque-forming units of the pathogen. After $10 \mathrm{~min}$ of incubation at room temperature, $2 \mathrm{~mL}$ of TM10 was added and the tubes were incubated in an orbital shaker for $16 \mathrm{~h}$ at $37^{\circ} \mathrm{C}$. Samples were taken from this culture, and the count of the non-altruistic host $S$ was determined on LB agar containing $20 \mu \mathrm{g}$ $\mathrm{mL}^{-1}$ kanamycin, while the altruistic-type host A count was determined on LB with 25 $\mu \mathrm{g} \mathrm{mL} \mathrm{m}^{-1}$ chloramphenicol. The phage titer (the number of viable pathogens) was assayed on E. coli BMF1.

To investigate infection in the presence of spatial structure, the host and the pathogen were grown in a soft agar matrix spread over a bottom agar plate. To initiate the soft agar culture, $10^{4}$ to $10^{7}$ cells of each type of host were mixed in various ratios (a total of $10^{7}$ cells) and $10^{6}$ plaque-forming units of phages were added to $1 \mathrm{~mL}$ of TM10. Ten minutes of incubation were allowed for adsorption, before $2 \mathrm{~mL}$ of molten $\left(50^{\circ} \mathrm{C}\right)$ top agar (TM10 with $0.6 \%$ agar) was added. The suspension was then poured onto Petri plates containing about $30 \mathrm{ml}$ of hardened bottom agar (TM10 with $1.0 \%$ agar). After an incubation period of 0 to $16 \mathrm{~h}$ at $37^{\circ} \mathrm{C}$, the soft agar matrix was scraped off into a tube containing $1 \mathrm{~mL}$ of tryptone broth (without maltose and agar) and vortexed for $30 \mathrm{sec}$ to liberate the host and pathogen from the soft agar, before the agar fragments were separated by centrifugation at $1600 \mathrm{~g}$ for $2 \mathrm{~min}$ at $4^{\circ} \mathrm{C}$ The counts of the pathogen and the ratio of the two hosts were measured as above.

Fluorescent microscopy. Fluorescent microscopic imaging was used in the presence of spatial structure, where the host and the pathogen were grown in a covered soft agar matrix spread over a bottom agar plate. To initiate the soft agar culture, $10^{6}$ to $10^{7}$ cells of each type host in various ratios (a total of $10^{7}$ cells), and $10^{6}$ plaque-forming units of the phage, were added to $1 \mathrm{~mL}$ of TM10 containing $10 \mu \mathrm{g} \mathrm{mL} \mathrm{L}^{-1}$ ampicillin. After $10 \mathrm{~min}$ of incubation to allow adsorption at room temperature, $2 \mathrm{~mL}$ of molten $\left(50^{\circ} \mathrm{C}\right)$ soft agar (TM10 with $0.6 \%$ agar) was added. Then, $0.6 \mathrm{~mL}$ of the soft agar suspension was poured onto a Petri plate containing about $30 \mathrm{~mL}$ of hardened bottom agar (TM10 with $1.0 \%$ agar, and $10 \mu \mathrm{g} \mathrm{mL}^{-1}$ ampicillin). After $10 \mathrm{~min}$ of cooling at $4^{\circ} \mathrm{C}, 0.6 \mathrm{~mL}$ of molten $\left(50^{\circ} \mathrm{C}\right)$ soft agar (TM10 with $0.6 \%$ agar) was poured over to produce an overlay of top agar. After incubation for $16 \mathrm{~h}$ at $37^{\circ} \mathrm{C}$, the plates were stored at $4^{\circ} \mathrm{C}$

mRFP fluorescence was imaged with 510-560 nm excitation, a $590 \mathrm{~nm}$ emission filter, and a $575 \mathrm{~nm}$ diachroic mirror. GFPuv fluorescence was imaged with 465 $495 \mathrm{~nm}$ excitation, a 515-555 $\mathrm{nm}$ emission filter, and a $505 \mathrm{~nm}$ diachroic mirror.

Identification and characterization of mutants. Host mutants resistant to pathogen were detected as colony formers on polypeptone agar plates $(1.0 \%(\mathrm{w} / \mathrm{v})$ polypeptone, $0.5 \%(\mathrm{w} / \mathrm{v}) \mathrm{NaCl}, 0.2 \%$ maltose, $10 \mathrm{mM} \mathrm{MgSO}_{4}$, and $1.3 \%$ Bactoagar) seeded with $10^{9}$

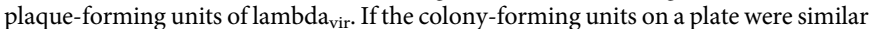
to that on polypeptone agar plate without lambda ${ }_{\text {vir }}$, the bacterium was defined as resistant. Otherwise, they were judged as sensitive.

A pvuIIM- mutant of the pathogen was determined by plaque assay. When the pathogen titer on the altruistic host was similar to that of the non-altruistic host, it was judged as $p v u I I M^{-}$. Otherwise, it was judged as $p v u I I M^{+}$. The ratio of the number 
measured in a restricting host (R.PvuII $\left.{ }^{+}, \mathrm{BMF} 35\right)$ to the number measured in a nonrestricting host (R.PvuII ${ }^{-}$, BMF37) was a measure of defects in the pathogen's methyltransferase (M.PvuII) activity.

Sequence determination. The phage suspensions were prepared from a single plaque in $0.1 \mathrm{~mL}$ of $0.1 \mathrm{M} \mathrm{NaCl}, 5 \mathrm{mM} \mathrm{MgSO}$, $50 \mathrm{mM}$ Tris- $\mathrm{HCl}$, and $0.01 \%$ gelatin (SM buffer). A $5.1 \mathrm{~kb}$ fragment containing the pvuIIM gene was amplified by PCR using the primer LEF1-for (5'-TGTTTTACCACACCCATTCC-3') and LEF1-rev (5'-ATCCCCATTCTGCAATGTGCG-3'). The temperature cycling in a program temperature control system (ASTEC) was as follows: $10 \mathrm{~s}$ at $98^{\circ} \mathrm{C}, 15 \mathrm{~s}$ at $55^{\circ} \mathrm{C}$, and $5 \mathrm{~min} 10 \mathrm{~s}$ at $72^{\circ} \mathrm{C}$ for 30 cycles. We determined the sequences using the primers PvuIIM_pcr-for (5'-TTAGCTCTTCAGGCTTCTGA-3'), PvuIIM_seq-rev (5'-CGGCTAAACTCGATAGAACA-3'), Primer 2 (5'-GGGGCGTACATGAAAGGCGT-3'), and Primer 5 (5' CTCGGGTAACTTAGCAGGA-3').

Model. Definitions of variables, parameters, and terms are summarized in Table S3. We embedded our virtual host-pathogen community in two layers of lattice, each composed of $10000 \times 10000$ regular squares (Fig. S5). The upper lattice contained the host population, where each square was either empty or occupied by: a susceptible host (S: non-altruistic type), a resistant susceptible host ( $S^{R}$ : mutant form of $S$, resistant to any type of pathogen), an infected host (I: infected form of S by P), an infected host ( $\mathrm{I}^{\mathrm{Q}}$ : infected form of $\mathrm{S}$ or $\mathrm{A}$ by $\left.\mathrm{Q}\right)$, an altruistic host (A: suicide type), a resistant altruistic host ( $\mathrm{A}^{\mathrm{R}}$ : mutant form of $\mathrm{A}$, resistant to any type of pathogen) (Fig. S5). The lower lattice contained the pathogen population, where each square was either empty or occupied by pathogens (P: induces suicide in S host) or mutant pathogens (Q: mutant defective in induction of host suicide) (Fig. S5).

With spatial structure, the reproduction of $S\left(S^{R}, A\right.$, or $\left.A^{R}\right)$ filled a neighboring empty site at a rate of $(1-\mu) r / 4$ (Fig. S5a). Mutational reproduction of S (or A) filled a neighboring empty site at a rate of $r \mu / 4$ (Fig. S5b). P (or Q) infection of S (or A) occurred in the upper site and neighboring sites at a rate of $(1-\mu) \beta / 113$ (Fig. S5c, d). P infection was associated with $\mathrm{P}$ to $\mathrm{Q}$ mutation, and occurred in $\mathrm{S}$ (or $\mathrm{A}$ ) in the upper site and neighboring sites at a rate of $\mu \beta / 113$ (Fig. S5e). The death of I was accompanied by $\mathrm{P}$ release to the lower site after $\tau$ min from infection (Fig. S5g). P (or Q) was absorbed by $\mathrm{S}$ (I or A) in the upper site and neighboring sites at a rate of $a / 113$ (Fig. S5f).

When spatial structure was absent, host reproduction, pathogen infection, and adsorption occurred at any site.

Details of the model are described in the SI Text 2.

1. Ebert, D. \& Mangin, K. L. The influence of host demography on the evolution of virulence of a microsporidian gut parasite. Evolution 51, 1828-1837 (1997).

2. May, R. M. \& Anderson, R. M. Epidemiology and Genetics in the Coevolution of Parasites and Hosts. Proceedings of the Royal Society of London Series B-Biological Sciences 219, 281-313 (1983).

3. May, R. M. \& Nowak, M. A. Superinfection, Metapopulation Dynamics, and the Evolution of Diversity. Journal of Theoretical Biology 170, 95-114 (1994).

4. Weinrauch, Y. \& Zychlinsky, A. The induction of apoptosis by bacterial pathogens. Annu Rev Microbiol 53, 155-87 (1999).

5. Belser, J. A. et al. Contemporary North American influenza H7 viruses possess human receptor specificity: Implications for virus transmissibility. Proceedings of the National Academy of Sciences of the United States of America 105, 7558-7563 (2008).

6. Chopin, M. C., Chopin, A. \& Bidnenko, E. Phage abortive infection in lactococci: variations on a theme. Current Opinion in Microbiology 8, 473-479 (2005).

7. Fukuda, E., Kaminska, K. H., Bujnicki, J. M. \& Kobayashi, I. Cell death upon epigenetic genome methylation: a novel function of methyl-specific deoxyribonucleases. Genome Biology 9, - (2008).

8. Brockhurst, M. A., Buckling, A. \& Rainey, P. B. Spatial heterogeneity and the stability of host-parasite coexistence. Journal of Evolutionary Biology 19, 374-379 (2006).

9. Haraguchi, Y. \& Sasaki, A. The evolution of parasite virulence and transmission rate in a spatially structured population. Journal of Theoretical Biology 203, 85-96 (2000).
10. Kamo, M., Sasaki, A. \& Boots, M. The role of trade-off shapes in the evolution of parasites in spatial host populations: An approximate analytical approach. Journal of Theoretical Biology 244, 588-596 (2007).

11. Sato, K., Matsuda, H. \& Sasaki, A. Pathogen Invasion and Host Extinction in Lattice Structured Populations. Journal of Mathematical Biology 32, 251-268 (1994).

12. Chao, L. \& Levin, B. R. Structured Habitats and the Evolution of Anticompetitor Toxins in Bacteria. Proceedings of the National Academy of Sciences of the United States of America-Biological Sciences 78, 6324-6328 (1981).

13. Kerr, B., Riley, M. A., Feldman, M. W. \& Bohannan, B. J. M. Local dispersal promotes biodiversity in a real-life game of rock-paper-scissors. Nature 418, 171-174 (2002).

14. Mochizuki, A., Yahara, K, Kobayashi, I. \& Iwasa, Y. Genetic addiction: selfish gene's strategy for symbiosis in the genome. Genetics 172, 1309-1323 (2006).

15. Schrag, S. J. \& Mittler, J. E. Host-parasite coexistence: The role of spatial refuges in stabilizing bacteria-phage interactions. American Naturalist 148, 348-377 (1996).

16. Griffin, A. S. \& West, S. A. Kin selection: fact and fiction. Trends in Ecology \& Evolution 17, 15-21 (2002).

17. Ross-Gillespie, A., Gardner, A., West, S. A. \& Griffin, A. S. Frequency dependence and cooperation: theory and a test with bacteria. American Naturalist 170, 331-342 (2007)

18. Ackermann, M. et al. Self-destructive cooperation mediated by phenotypic noise. Nature 454, 987-990 (2008).

19. James, E. R. \& Green, D. R. Infection and the origins of apoptosis. Cell Death and Differentiation 9, 355-357 (2002).

20. Rueppell, O., Hayworth, M. K. \& Ross, N. P. Altruistic self-removal of healthcompromised honey bee workers from their hive. Journal of Evolutionary Biology 23, 1538-1546 (2010).

21. Handa, N., Amitani, I., Gumlaw, N., Sandler, S. J. \& Kowalczykowski, S. C. Single Molecule Analysis of a Red Fluorescent RecA Protein Reveals a Defect in Nucleoprotein Filament Nucleation That Relates to Its Reduced Biological Functions. Journal of Biological Chemistry 284, 18664-18673 (2009).

22. Ohashi, Y., Ohshima, H., Tsuge, K. \& Itaya, M. Far different levels of gene expression provided by an oriented cloning system in Bacillus subtilis and Escherichia coli. Fems Microbiology Letters 221, 125-130 (2003).

23. Hendrix, R. W., Roberts, J. W., Stahl, F. W. \& Weisberg, R. A. lambda II (Cold Spring Harbor Laboratory, 1983).

\section{Acknowledgments}

The supercomputing resource was provided by the Human Genome Center (Univ. of Tokyo). I.K. was funded by the global COE project "Genome Information Big Bang" from the Ministry of Education, Culture, Sports, Science, and Technology (MEXT) of the Japanese government. a 'Grants-in-Aid for Scientific Research' from the Japan Society for the Promotion of Science (JSPS) (21370001), and foundation for the Fusion Of Science and Technology (FOST)

\section{Author contributions}

I.K. designed the research; A.S. guided the modeling and simulation; M.F. performed the research; I.K, A.S. and M.F. wrote the paper.

\section{Additional information}

Supplementary information accompanies this paper at http://www.nature.com/ scientificreports

Competing financial interests: The authors declare no competing financial interests.

License: This work is licensed under a Creative Commons

Attribution-NonCommercial-ShareAlike 3.0 Unported License. To view a copy of this license, visit http://creativecommons.org/licenses/by-nc-sa/3.0/

How to cite this article: Fukuyo, M., Sasaki, A. \& Kobayashi, I. Success of a suicidal defense strategy against infection in a structured habitat. Sci. Rep. 2, 238; DOI:10.1038/srep00238 (2012). 